\title{
Bazı Sebzelerde Tohum Uygulamalanında Mekanizasyon Olanaklarının Incelenmesi
}

\author{
Hülya KARABAŞ ${ }^{1} \quad$ Ahmet ÇOLAK ${ }^{2} \quad$ Ibrahim DEMIR ${ }^{3}$
}

Geliş tarihi : 31.01 .2001

\begin{abstract}
Özet: Bu çalişmada, bir tohum kalitesini geliștirme düzeneği tasarımlanıp imal edilmiş, bu düzenekle soğan ve biber tohumiarı uzerinde osmotik priming uygulaması gerçekleştirilmiştir. Bu uygulama lle yüksek çimlenme oranına hızlı çıkıs gücüne, çıkış homojenliğine ve duşok çimlenme hızına sahip kaliteli tohumlar elde etmek amaçlanmıştır. Osmotik priming uygulaması için geliştírilen düzeneğin bazı aşamalarında otomatik kumanda sağlanmıştır.

Tohum kalitesini geliştirme düzeneğinde distile su ve PEG 6000 solüsyonu lie gerçekleştirilen osmotik priming uygulamasında belli zaman periyotlarında sabit sıcaklıkta, solüsyona sürekli hava verilerek karıștırma sağlanarak gerçekleştirilen uygulamalar sonrasında, tohumlar yıkanip etôvde kurutuimuşlardır. ISTA kurallarına göre yapılan 14 günlük çimlendirme deneylerinden sonra yapılan Duncan testi sonuçlarina göre sog̉an ve biber tohumlarında çıkış homojenliği sağlanmıștır. Priming uygulanmıș tohumlarda kontrol tohumlarına göre daha yüksek çimlenme gücũ ve daha yöksek çimlenme hızı elde ediimiştir.
\end{abstract}

Anahtar Kelimeler : Osmotik priming, soğan, biber, otomatik kontrol

\section{The Analyses of Mechanisation Possibilities in Some Kind of Vegetable Seed Treatment}

\begin{abstract}
In this work, using mechanism of produced seed treatment quality an osmotic priming application has been confirmed on onion and pepper seeds. The aim of this practise is to achieve good quality seeds which posses high germination percentage, speed in seedling emergence homogeneousness emergence and decrease in mean germination time. In some phases of the mechanism which is produced for osmotic priming application an automatic controller is being ensured.

In the mechanism of treating good quality seedling, distilled water and PEG 6000 solution has been used to achieve osmotic priming application and this is confirmed by given air perpetually to the solution in uniform temperature and certain period. After providing stirring application the seeds are washed and dried in incubator.

According to the results of DUNCAN test, which was made after the 14 days seedling tests of ISTA, it is approved that a homogeneousness emergence has been provided in onion and pepper seeds in the primed seeds in comparison with untreated seeds there is an increase in the speed of seedling performance and decrease in mean germination. A conformable priming time has been stated for onion and pepper seeds.
\end{abstract}

Key Words: Osmotic priming, onion, pepper, automatic control

\section{Giriş}

Başarili bir bitkisel äretimin ilk şarti kaliteli tohumdur. Kaliteli tohum; yäksek çimlenme oranı, hızı, çıkış gücu ve homojenliğe sahip olmalıdır. Sebze yetiştiriciliğinde çıkışın gecikmesi ile tohumlardan daha erken toprak yôzüne çıkan yabancı otlar, sebze tohumları ile rekabete girerek çıkıșı daha da geciktirmektedirler. Bir örnek (homojen) ve hızlı olmayan çıkıș, doğrudan hasat ișleminin gecikmesine neden olmaktadır. Bir örnek olmayan çıkıs sonucunda farklı olgunluk derecesindeki, ürünün bir kısmı tam hasat olgunluğuna erişmeden hasat edilmektedir. Bu ise özellikle hasadin makine ile yapilması durumunda da hasat sonu kayıpların! artırmaktadır. Aynı zamanda bu durum ureticinin optimum hasat zamaninın belirlenmesi konusunda doğru ve rahat karar verememesine neden olmaktadir

Değişik amaçlara yônelik olarak tohumlara fiziksel, kimyasal veya biyolojik uygulamalar yapilmaktadir

Yăksek Lisans Tez'inden hazırlanmıștır.

1. Sakarya Üniv. Akyazı Meslek Yoksekokulu-Akyazi-Sakarya

2. Ankara Üniv. Ziraat Fak. Tarım Makinaları Bölümü-Ankara

3. Ankara Üniv. Ziraat Fak. Bahçe Bitkileri Bölümü-Ankara
Çimlenme hızını ve oranını artırmak için ekim öncesi islatma ve tohumları osmotik çözeltilerde tutma en çok kullanilan yỏntemler arasındadir (Heydecker ve ark. 1977).

Çimlenmeyi uyarıcı uygulamalar özellikle toprak sıcaklığının dûsük olduğu erken ilkbahar ve sonbahar ekimlerinde fide çıkış oranıni artırmada etkili bulunmuştur (Szafirowska ve ark, 1981).

Tohumiarın osmotik çózeltilerde tutulması ile tohumun içine çimlenme mekanizmasını başlatacak kadar suyun girmesi sağlanmakta ve tohum içinde çözonen maddelerin tohum dışına çıkısı engellenebilmektedir. Osmotik çözeltilerde tutularak, tohumda çimlenme mekanizmasının başlatılması olayına çimlenmeyi uyarma anlamında Priming (Osmotic conditioning), bu uygulamayı görnûş tohumlara ise çimlenmesi uyarılmış tohum anlaminda primed seed (Osmoconditioned seed) 
denilmektedir (Nienow 1987). Tohum uygulamaları çimlenme ve fide çıkış hızındaki artışın yanısıra, birörnek gelişim ve tohum dinlenmesinin ortadan kaldinımasını da sağlamaktadır (Cantliffe ve ark. 1987). Ilk olarak laboratuvarlarda petri kaplari içinde uygulama imkant bulan osmotik priming yöntemi daha sonra çeşiti tipte bioreaktörlerle sınırlı miktarda tohum kullanılarak uygulanmaya başlanmıştır.

Sebze tohumlarında farklı sıcaklık ve süreler kullanılarak yapilan tohum uyarma (priming) uygulamaları sonucunda, çimlenmenin teşvik edildiğine, çıkış hızının arttığına ve çıkış sürelerinin kısaldığına ilişkin başarılı çalışmalar bulunmaktadır (Cantliffe ve ark. 1987).

Ükemizde tohum kalitesini artırıcı uygulamalara ilişkin bilimsel araștıma bazında çalışmalar bulunmakla birlikte uygulamaların mekanizasyonu ve böyük miktarlardaki tohumların işienmesi konusunda yeterli çalışma bulunmamaktadır. Bu araştırma bu tip bir uygulama düzeneğinin üretimini hedeflemektedir.

\section{Materyal ve Yöntem}

Çalıșmada materyal olarak soğan (Allium cepa L.cV. Çorum) ve biber (Capsicum annum L. CV. Demre Sivrisi) tohumları kullanılmıştır. Bu tohumlar çalışmada geliştirilen Tohum Kalitesini Geliştirme Düzeneği (TKGD) kullanılarak osmotik priming ve nemlendirme uygulamalarına tabi tutulmuştur.

Çimlenme mekanizmasını harekete geçirmek amacıyla osmotik basinci sifir olan distile su ve Michel ve Kaufmann (1973)'a göre hazırlanan $20^{\circ} \mathrm{C}$ 'deki osmotik basıncı -1.0 MPa olan PEG 6000 solüsyonu kullanılmıștir.

Priming uygulamasını izleyen çimlendirme testlerinde ise $9 \mathrm{~cm}$.lik petri kapları ve filtre kağitları kullanılmıştır.
Osmotik priming uygulamalarında bioreaktörlerin kullanılabilmesinden yola çıkılarak, sebze tohumlarının buyauk miktarları üzerinde uygulama imkanı yaratabilmek ve uygulamanın bazı aşamalarında otomasyon sağlayabilmek amacıyla şekil 1'de görülen Tohum Kalitesini Geliştirme Düzeneği geliştirilmiştir.

Imalatı gerçekleştirilen TKGD yerine getirdiği fonksiyonlar gơz őnōne alındığında beş ana bölumden oluşmaktadır. Bunlar, solüsyon haznesi, tohum taşıma arabası, duşlama sistemi, kurutma kabini ve elektrikli kumanda panosudur.

TKGD $1320 \mathrm{~mm}$ yăksekliğe ve $1600 \mathrm{~mm}$ uzunluğa sahiptir. Şekil 1'de 1.Solüsyon haznesi, 2. Termostath Isitici, 3. Hava hortumu, 4. Hava hortumu, 5. Hava yol verme vanası, 6.Elektrikli küresel vana, 7. Tohum taşıma arabası, 8. Elektrikli kumanda panosu, 9. Sicaklık kontrol cihazı, 10. Zaman kontrol cihazı (timer), 11. Ana buton, 12. Küresel vana kapama butonu, 13. Küresel vana açma butonu, 14. Zaman kontrol butonu, 15. Duş başlığı. 16. Üçlo elektrik prizi, 17. Hava pompası, 18. Kurutma kabini, 19. Konik gövde, 20. Tahliye kanalı, 21. Taşıyıcı ayak, 22. Hava dağıtıcı meme, 23. Elektrik prizi, 24. Solüsyon haznesini taşıyan ayak'dır.

Konik şekilli olan solüsyon haznesi (Şekil 2) saydam fiberglas malzemeden 6 litre solüsyon kapasiteli olarak imal edilmiştir.

Solüsyon haznesinin içinde yôkselen sıcaklık değerlerini kontrol etmek için kullanilan termostatli bir Isıtıcı bulunmaktadır. Denemeler süresince bu termostatı ısıtıcı yardımıyla solûsyon sıcaklığı $20^{\circ} \mathrm{C}$ 'de tutulmuştur. Solusyon haznesi içinde yer alan ikinci bir eleman da iki adet hava hortumudur. Bu hortumlara hava pompas! aracılığı ile $1 \mathrm{l} / \mathrm{min}$ verdi ile lletilen atmosfer havası sayesinde solüsyonun karıştırılmasına ve işlem süresince tohumların ihtiyacı olan oksijenin sağlanmasına çalıșılmıştır.

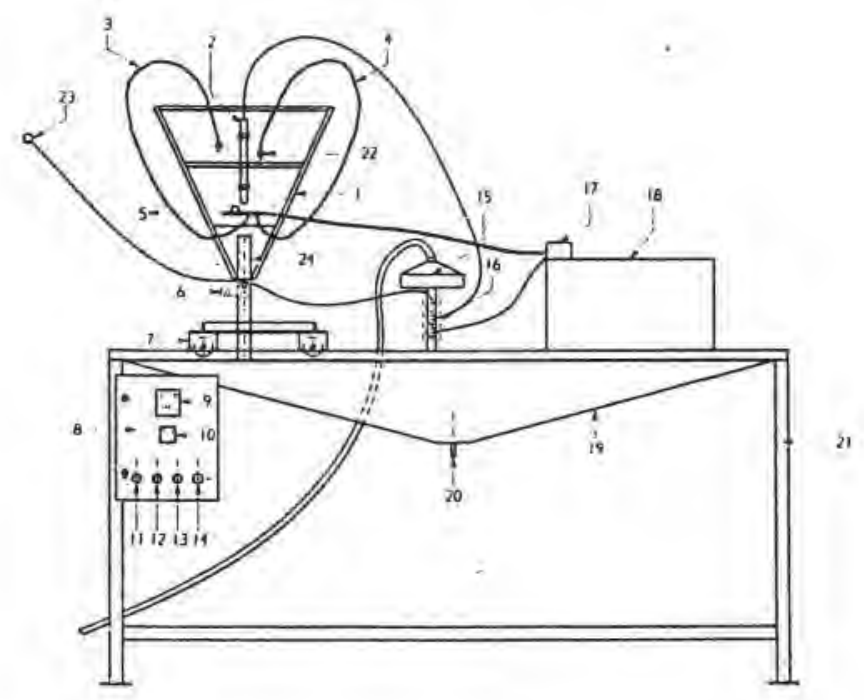

Şekil 1. Tohum kalitesini geliştirme duzeneğinin şematik görunuaşü 


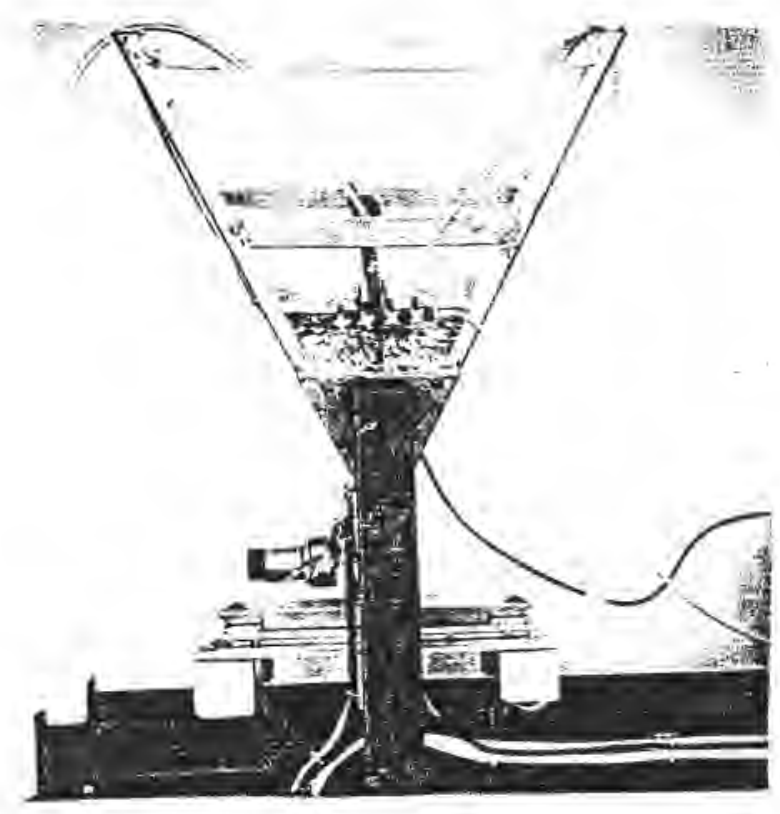

Şekil 2. Solüsyon haznesi

Solüsyon haznesinin en alt uç noktasına milisaniye seviyesinde açma kapama yapabilen elektrikji koresel vana yerleştiritmiștir. Bu vana ile çalışmada 12,24, 48 ve 96 saatlik dort ayri zaman periyodunda uygulanan osmotik priming işlemlerinin uygulama sürelerine Hanyoung marka LF 4-A model timer ile otomatik olarak kumanda edilmiştir.

Uygulama süresi tamamlandiğinda elektrikli kumanda panosu üzerinde yer almış olan küresel vana açma ve kapama butonları sayesinde elle veya zaman kontrol butonunun kumanda ettiği timer yardımıyla küresel vana açılarak solüsyon haznesi içindeki distile su veya PEG 6000, solüsyonu ile tohumların tohum taşıma arabası uzerine düşmesi sağlanmıştır. Tohumlar tohum taşıma arabası uzerinde bulunan $1 \mathrm{~mm}$ çaplı deliklere sahip metal elek üzerinde kalırken, solusyon bu elekten geçerek tahliye kanalına ulaşmaktadir.

Metal elek üzerinde kalan tohumlar solüsyondan arındırılmak için duş başlığı altında yıkanmaktadır. Yikanan tohumlar tohum taşıma arabasına verilen hareketle kurutma kabininin içine getirimektedir. Hanyoung marka DF 7 model sicaklik kontrol cihazı sayesinde kumanda edilen kurutma kabini $22^{\circ} \mathrm{C}$ 'lik. sabit sıcaklığa ayarlanmıştır. Kabinde Pt 100 tipi algilayıcı kullanilmiştır. Tohumlar kabin içinde 10 dakika süreyle on kurutma ișlemine tabi tutulmuştur.

TKGD kullanilarak soğan ve biber tohumları uzerinde 3 tekerrörlu olarak gerçekleştirilen makine denemelerinde her tekerrürde 100 adet tohuma uygulama yapılmıştı.

Makine denemeleri sonrasında ôn kurutmadan çıkan tohumlar direkt güneş ışığı olmayan aydinlık bir ortamda, uygulama öncesi nem içeriklerine ulaşmaları için 2 gün süreyle filtre kağıtları uzerinde kurutulmuștur.
Kurutma işlemi tamamlanan tohumların cam saklama şişeleri içerisinde ekim zamanına kadar serin bir ortamda depolanmaları sağlanmıştır.

Osmotik priming uygulaması görmüș tohumların çimlendirme testleri ISTA (Uluslararası Tohum Test Birliği kurallarına göre (Anonymous 1993) yapılmıştir. Petri kaplarina 3 tekerrarla ve her tekerrurde 25 tohum olacak şekilde ekilen tohumlar $20^{\circ} \mathrm{C}$ sıcaklikta 14 gün sureyle etavde tutulmuștur.

Çimlendirme testlerinde sayım, kökcuk ucu çıplak gözle görülebilen tohumlar çimlenmiş kabul edilerek, sayımın gerçekleştirildiği günlerde bu tohumların atılması yolu ile yapilmıştır. Sayımı yapilan soğan ve biber tohumiarınin her tekerrurdeki çimlenme găçleri ve çimlenme hızlari hesaplanmiştir.

Deneme; tesadüf parselleri deneme desenine göre değerlendirilmiș, uygulamalar ve tohum kalitesini geliştirme dazeneği arasındaki farkliliklar \% 5 hata sinirlarında DUNCAN testi ile karşılaștırilmiştır.

\section{Bulgular ve Tartışa}

Soğan tohumlarinda dort ayri uygulama süresinde uç tekerrüria olarak yapilan makine uygulamaları sonucunda cimlenme gücû açısından kontrol ve uygulamalar arası farklılikları belirlemek amacıyla yapılan DUNCAN testi sonuçarı çizelge 1:'de verilmiştir.

Çizelge 1 incelendiğinde TKGD ile yapılan makine tekerrúrleri arasında istatistiksel olarak onnemli bir farklılık olmadığı göralmektedir. Soğan tohumlarının çimlenme gücä, uygulama süreleri bakımından incelendiğinde istatistiksel farklılık belirlenmiştir. Kontrol tohumlarında \% 86.67 olan çimlenme gücü 96 saatlik PEG 6000 uygulamasında \%90.67'ye yükselmiştir.

Çizelge 2'de de biber tohumlarının çimlenme oraninda meydana gelen uygulamalar ve kontrol tohumlan arasindaki farkliliklan belirlemek amacıyla yapilan DUNCAN testi sonuçları goralmektedir.

Çizelge 2'den de anlaşıldığı gibi TKGD ile yapilan makine tekerrürleri arasındaki fark istatistiksel olarak onemlidir. Biber tohumlarının çimienme güca, uygulama sâreleri bakımından incelendiğinde yine istatistiksel farklılık belirlenmiştir. 12 ve 48 saat uygulamalan diğer sürelerden daha iyi sonuçlar vermiştir.

Çizelge 3'te soğan tohumiarının çimlenme hizında meydana gelen kontrol ve uygulamalar arasindaki farklilikları belirlemek amaciyla yapilan DUNCAN testi sonuçlar görülmektedir.

Çizelge 3 incelendiğinde makine tekerrúrlerinin, soğan tohumlarının çimienme hızında istatistiksel anlamda önemli bir fark yaratmadiğı da göralmektedit. Kontrol tohumlarında 4.45 gön olan çimlenme hizınin 12 saatlik uygulamada 4.19 güne dusştügü göralmektedir. 
Çizelge 1. PEG 6000 ile yapılan uygulamanın makine tekerrürleri ve uygulama sürelerine göre soğan tohumlarında çimlenme oranı Uzerine etkisi

\begin{tabular}{|c|c|c|c|c|}
\hline \multirow{2}{*}{$\begin{array}{c}\text { Uyguiama } \\
\text { Süreleri }\end{array}$} & \multicolumn{2}{|r|}{ Tekerrür } & & \multirow[b]{2}{*}{ Ortalamalar } \\
\hline & 1.Tekerrär & 2.Tekerrür & 3.Tekerrür & \\
\hline 12 Saat & 84,00 & 92,00 & 85,33 & $87,11 \mathrm{ab}$ \\
\hline 24 Saat & 89,33 & 85,33 & 89,33 & $88,00 \mathrm{a}$ \\
\hline 48 Saat & 78,67 & 84,00 & 81,33 & $81,33 b$ \\
\hline 96 Saat & 89,33 & 92,00 & 90,67 & 90,67 a \\
\hline Kontrol & 86,67 & 86,67 & 86,67 & $86,67 \mathrm{ab}$ \\
\hline Ortalamalar & $85,60 a$ & $88,00 a$ & 86,67 a & \\
\hline
\end{tabular}

* Farklı harfleri taşıyan ortalamalar arasındaki fark $\% 5$ dûzeyinde önemlidir.

Çizelge 2. PEG 6000 ile yapılan uygulamaların makine tekerrürleri ve uygulama sürelerìne göre biber tohumlanında çimlenme oranı 0zerine etkisi.

\begin{tabular}{|c|c|c|c|c|}
\hline \multirow{2}{*}{$\begin{array}{c}\text { Uygulama } \\
\text { Süreleri }\end{array}$} & \multicolumn{2}{|r|}{ Tekerrũr } & & \multirow[b]{2}{*}{ Ortalamalar } \\
\hline & 1.Tekerrür & 2.Tekerrür & 3.Tekerrür & \\
\hline 12 Saat & 68,00 & 69,33 & 60,00 & $65,78 \mathrm{~b}$ \\
\hline 24 Saat & 81,33 & 73,33 & 80,00 & $78,22 a$ \\
\hline 48 Saat & 68,00 & 58,67 & 56,00 & $60,89 \mathrm{~b}$ \\
\hline 96 Saat & 84,00 & 73,33 & 68,00 & 75,11 a \\
\hline Kontrol & 80,00 & 80,00 & 80,00 & 80,00 a \\
\hline Ortalamalar & $76,27 \mathrm{a}$ & $70,93 \mathrm{~b}$ & $68,80 \mathrm{~b}$ & \\
\hline
\end{tabular}

* Farkı harfleri tașıyan ortalamalar arasında $\% 5$ dozeyinde farklilık vardır.

Çizelge 3. Makine tekerrürleri ve uygulama sürelerinin soğan tohumlarının çimlenme hızı üzerine olan etkileri.

\begin{tabular}{|c|c|c|c|c|}
\hline \multirow{2}{*}{$\begin{array}{c}\text { Uygulama } \\
\text { Sureleri }\end{array}$} & \multicolumn{3}{|c|}{ Makine } & \multirow{2}{*}{ Ortalamalar } \\
\cline { 2 - 5 } & 1, Tekerrür & 2.Tekerrürlerír & 3. Tekerrür & $4,19 \mathrm{a}$ \\
\hline 12 Saat & 4,43 & 3,98 & 4,17 & $4,34 \mathrm{a}$ \\
\hline 24 Saat & 4,24 & 4,50 & 4,28 & $4,40 \mathrm{a}$ \\
\hline 48 Saat & 4,81 & 4,19 & 4,21 & $4,34 \mathrm{a}$ \\
\hline 96 Saat & 4,49 & 4,49 & 4,33 & $4,45 \mathrm{a}$ \\
\hline Kontrol & 4,45 & 4,45 & 4,45 & $4,29 \mathrm{a}$ \\
\hline Ortalamalar & $4,49 \mathrm{a}$ & $4,32 \mathrm{a}$ & 45 & \\
\hline
\end{tabular}

* Farklı harfleri taşıyan ortalamalar arasında Duncan testine göre 0.95 güvenirlilik sınırları içinde önemli farklılik vardır.

Çizelge 4. Makine tekerrürleri ve uygulama sürelerinin biber tohumlarının çimlenme hızı üzerine olan etkileri.

\begin{tabular}{|c|c|c|c|c|}
\hline \multirow{2}{*}{$\begin{array}{c}\text { Uygulama } \\
\text { Süreleri }\end{array}$} & \multicolumn{2}{|c|}{ Makine } & \multirow{2}{*}{ Ortalamalar } \\
\cline { 2 - 5 } & 1. Tekerrür & 2. Tekerrürleri & 3. Tekerrür & $4,79 \mathrm{~b}$ \\
\hline 12 Saat & 4,47 & 4,39 & 5,51 & $4,79 \mathrm{~b}$ \\
\hline 24 Saat & 5,06 & 4,81 & 4,50 & $4,22 \mathrm{c}$ \\
\hline 48 Saat & 4,25 & 4,19 & 4,23 & $4,39 \mathrm{bc}$ \\
\hline 96 Saat & 4,20 & 4,57 & 4,38 & $6,34 \mathrm{a}$ \\
\hline Kontrol & 6,34 & 6,34 & 6,34 & $4,99 \mathrm{a}$ \\
\hline Ortalamalar & $4,86 \mathrm{a}$ & $4,86 \mathrm{a}$ & \\
\hline
\end{tabular}

- Farkı harfleri taşıyan ortalamalar arasında Dunçan testine göre 0.95 güvenirlilik sınırları içinde önemli farklılı vardır.

Çizelge 4'te ise biber tohumlarının çimlenme hizında meydana gelen kontrol ve uygulamalar arasındaki farklılikları beliriemek amacıyla yapılan DUNCAN testi sonuçları görulmektedir.

Çizelge 4 incelendiğinde makine tekerrürlerinin biber tohumlannın çimlenme hızında istatistiksel bir fark yaratmadığı görülmektedir. Kontrol tohumlarında 6.34 gün olan çimlenme hızınin 48 saatlik distile su uygulamasında 4.22 güne düştăğua görülmektedir.

\section{Sonuç}

Tohumlara osmotik piriming uygulamasının bașlıca nedenleri yuaksek çimlenme oranına, hızlı çıkış gücüne çıkıș homojenliğine ve dusşak çimlenme hızına sahip tohumlar elde etmektir. Imalatı gerçekleştirilen TKGD'de soğan ve biber tohumlarına uygulanan priming yöntemi sonucunda kısmen bu amaçlara ulaşılmıştır.

Düzeneğin prototip olması, sıcaklık gibi bazı etkenlerde kontrolün çok hassas şekilde sağlanamamış 
olması, soğan tohumlarının çimlenme hızında kontrol tohumlarına oranla belirgin bir farkın gözlenememiş olması ve biber tohumlarının çimlenme gücünün kontrol tohumlarına oranla düşük olması çalışmanın olumsuz sonuçlarıdır.

Bunların sebebi solüsyon haznesi içindeki solüsyon sıcaklığının artan hava sıcaklığının etkisi ile zaman zaman kontrol dışına çıkmasıdır. Bunun yanısıra kullanılan plastik haznenin sonuçları etkilemiş olması da mümkündür.

Literatürdeki diğer çalışmalarda da (Nienow ve Brocklhurst 1987) uygulama yöntemindeki farklılığa bağlı olarak, değişik sebeplere dayalı olumsuz sonuçlar bulunmaktadır.

Bunların yanısıra soğan tohumlarında görülen yüksek çimlenme oranı, biber tohumlarında da yüksek çimlenme hızı başarılı sonuçlar olarak değerlendirilmektedir.

Bundan sonra yapılacak çalışmalarda geliştirilen düzeneğin değişik sebze türlerinde tohumların kalitesini artırmak amacıyla kullanılabilirliği test edilecektir.

\section{Kaynaklar}

Anonymous, 1985. International rules for seed testing. Seed Sci. and Technol., 13:421-463.

Anonymous, 1993. International rules for seed Testing. International Seed Testing Association (ISTA) Seed Sci. and Techn. 21, supplement .
Atkinson, B. 1974. Biological reactors. Pion Limited, 230 s., London.

Bujalski, W. and A. W. Nienow, 1991. Large scale osmotic priming of onion seeds:a comparison of different strategies for oxygenation. Scientia Horticulturae, 46: 13-24.

Cantliffe, D. J. and H. H. Bryan, 1987. Symposium on the timing of field production of vegetables. Acta Horticulture, 198 : 15-17.

Gray, D. 1983. Improving the quality of vegetable seeds. Span, 26: 46 .

Heydecker, W. and P. Coolbear, 1977. Seed treatments to improve performance survey and attempted prognosis. Seed Sci. and Technol., 5:353-425

Karabaș, H. 2000. Bazı sebzelerde tohum uygulamalarında mekanizasyon olanaklarının incelenmesi. Ankara Üniversitesi Fen Bilimleri Enstitüsū Yüksek Lisans Tezi. 37 s.,Ankara.

Michel, B. E. and M. R. Kaufmann, 1973. The osmotic potential of polyethylene glycol 6000. Plant Physiology, 51: 914-916.

Nienow, A. W. and P. A. Brocklhurst, 1987. Seed preparation for rapid germination engineering studies. International Conferance on Bioreactors and Biotransformations, 52-63.

Szafirowska, A., A. A. Khan and N. H. Peck, 1981. Osmoconditioning of carrot seeds improve seedling established an yield in cold soil. Agronomy Journal, 73: 845-848. 